\title{
Evaluation Research on the Decoupling Between the Economic Development and Energy Consumption in the Beijing-Tianjin-Hebei Region Under Dual Control Action*
}

\author{
Dan $\mathrm{Wu}^{1, * *}$ Chenhui $\mathrm{Ji}^{2}$ \\ ${ }^{1}$ School of Economics and Management, North China University of Technology, Beijing 100144, China \\ ${ }^{2}$ Department of Mathematics, Imperial College London, London SW7 2AZ, UK \\ ${ }^{* *}$ Corresponding author. Email: wu_daniel@163.com
}

\begin{abstract}
The "decoupling" of the economic development and energy consumption of the Beijing-Tianjin-Hebei region has become an academic hot point and research field of great concern to Beijing-Tianjin-Hebei government administrative departments and scholars. The existing literature mainly uses the classic decoupling discrimination framework, focusing on the total energy consumption in the Beijing-Tianjin-Hebei region, or the short-term decoupling situation evaluation and decoupling effect research of the industrial energy consumption in the Beijing-Tianjin-Hebei region. Few scholars comprehensively consider the total energy consumption and energy consumption of the three industries, decompose the driving effect of the changes in energy consumption of the three industries in the Beijing-Tianjin-Hebei region, evaluate the decoupling situation of economic development and energy consumption in the Beijing-Tianjin-Hebei region, and analyze the driving mechanism of the decoupling of energy consumption in the Beijing-Tianjin-Hebei region. To this end, this article adopts a Complete Decomposition Model, and through the decomposition of the driving effect of the decoupling of energy consumption in the three industries in the Beijing-Tianjin-Hebei region, it constructs an evaluation model for the decoupling of economic development and energy consumption under dual control action, determines the elastic coefficient of decoupling between economic development and energy consumption in the Beijing-TianjinHebei region, evaluates the decoupling situation of economic development and energy consumption in the Beijing-Tianjin-Hebei region, and deeply analyzes and demonstrates the driving mechanism of decoupling energy consumption in the Beijing-Tianjin-Hebei region. Researches show that the Beijing-Tianjin-Hebei region has not yet reached the peak of energy consumption and the "inflection point" of energy consumption increase. The effect of technological progress is the main driving force for accelerating the decoupling of economic development and energy consumption in the Beijing-Tianjin-Hebei region. By the "13th Five-Year Plan" period, the structural adjustment effect of the energy consumption of the primary industry in the Beijing-Tianjin-Hebei region has played a significant role, and the structural adjustment effect of the energy consumption of the secondary industry in the Tianjin-Hebei region has also played a significant role. In the future, the structural adjustment effect will become an important driving force for the decoupling of energy consumption and economic development in the Beijing-Tianjin-Hebei region together with the effect of technological progress. The structural adjustment effect of the tertiary industry energy consumption in the Beijing-Tianjin-Hebei region has not yet played a significant role. It is urgent to accelerate the structural transformation and upgrading of the tertiary industry, strengthen the structural adjustment effect of the tertiary industry energy consumption, and improve the energy consumption efficiency of the tertiary industry by improving the ability of energy technology innovation.
\end{abstract}

Keywords: Beijing-Tianjin-Hebei region, Energy, Decoupling, Effect, Mode, Mechanism. 


\section{INTRODUCTION}

With the acceleration of China's urbanization and industrialization, problems such as continuous growth in energy consumption and low overall energy consumption efficiency have become more prominent. In order to optimize China's energy system and solve the problem of increasing energy consumption demand, the Fifth Plenary Session of the 18th CPC National Congress clearly proposed the implementation of "dual control" action of total energy consumption and intensity. During the "13th Five-Year Plan" period, national ministries and commissions have successively introduced and implemented policies and measures such as the "13th Five-Year Plan for Energy Development" and the "Comprehensive Work Program of Energy Conservation and Emission Reduction During the 13th Five-Year Plan Period" to ensure the achievement of energy conservation and emission reduction targets. In June 2019, the "BP World Energy Statistics Yearbook 2019" released by British Petroleum Company pointed out that the combined energy demand growth of China, the United States and India accounted for more than $2 / 3$ of the global energy demand growth in 2018, and the contribution of China's primary energy growth was as high as $34 \%$, ranking first in the world. Therefore, the situation of China's energy conservation and emission reduction is severe. How to accelerate the decoupling of economic development and energy consumption and promote high-quality economic development has become an academic hot point of great concern to national government administrative department and scholars.

In the 1960s, the world first proposed the hot issue of "decoupling economic development from resources and the environment" [1]. And at the end of the 20th century, it clarified the important assertion of "improving resource utilization efficiency, reducing the proportion of resource input in economic output, realizing the decoupling of resource consumption and economic growth, and promoting sustainable development" [2][3], thereby

*Funds: Humanities and Social Science Fund Project of Ministry of Education (No. 21YJCZH176); General Project of Beijing Natural Science Foundation "Research on General Project of Beijing Natural Science Foundation "Research on the Bidirectional Optimal Adaptation of Water Resources and Industrial Structure Under the Coordinated Development of Beijing-Tianjin-Hebei Region" (No. 9202005); Yuyou Talent Project of North China University of Technology "Research on the Evaluation System of Beijing-Tianjin-Hebei Region's Resource Energy Consumption Management Performance and Its Cooperative Governance Capability from the Perspective of Technological Innovation" (No. XN020035). breaking the link between "resource consumption" and "economic wealth" [4][5]. Since the beginning of the 21st century, the decoupling of energy consumption and economic growth has attracted widespread attention from government departments and scholars all over the world. It has become a global consensus to promote the construction of an energy-saving society and achieve green growth. At present, the research on the decoupling of economic development and energy consumption in China and foreign countries has gradually matured, and the theoretical system of decoupling has been gradually improved. It has formed a classic OECD decoupling discrimination framework [6], divided three types of decoupling of decoupling, negative decoupling and connection, and subdivided into 8 types of decoupling situations [7][8]. Based on the national conditions of various countries, Chinese and foreign research institutions and academic circle have established the Tapio decoupling model, IPAT decoupling index method, IGT equation model method, elastic coefficient method and other decoupling evaluation methods [9][10][11][12], so as to carry out quantitative research on the decoupling relationship between economic development and energy consumption. For example, Kraft [9] and Paul [10][11][12] constructed decoupling indicators for energy consumption and carbon emission, respectively verifying the longterm decoupling relationship between economic development and energy consumption in the United States, India, Spain, and EU member states. Researches show that although the United States, the United Kingdom, Japan and other developed countries have achieved weak decoupling of economic development and energy consumption before 2000 on the basis of actively adopting energy-saving and emission-reduction policies and measures, strictly controlling total energy consumption and improving energy efficiency, a stable decoupling relationship has not yet been formed.

Existing literature and practice research results provide valuable experience for China to carry out the decoupling evaluation of economic development and energy consumption. Drawing on decoupling theory and international experience, Chinese scholars have conducted in-depth explorations on the decoupling of economic development and energy consumption at the national and regional levels from the perspectives of industrialization, urbanization, and energy carbon emission, and have achieved a number of important research results [13-23]. Studies have 
shown that the decoupling of economic development and energy consumption is simultaneously affected by economic development, technological progress, energy consumption control and utilization, and energy policies and measures. It is the inevitable result of the economic and social development indicators of per capita GDP reaching a certain level, which is mainly manifested in two decoupling modes of constraint and freedom, involving driving factors such as technological progress, demand structure, and inter-industry demand structure. The key driving force is energysaving technological progress, industrial structure optimization, and improvement of industry and overall energy consumption efficiency. The decoupling effect of production energy consumption in different industries is mainly reflected in the real energy-saving effect, the resource allocation effect, and the structural adjustment and relief effect. At present, the industrial energy consumption in the process of China's economic development is showing a relatively stable weak decoupling state, and China's total energy consumption is gradually changing from a weak decoupling stage to a strong decoupling stage. Under the premise of following the laws of national economic and social development, China will accelerate the absolute decoupling of economic development and energy consumption by 2030 through national development strategic planning to guide and strengthen dual control action.

Against the background of a major national strategy for coordinated development of the Beijing-Tianjin-Hebei region, the decoupling of economic development and energy consumption in the Beijing-Tianjin-Hebei region in the past five years has gradually attracted the attention of the academic world. Among them, Guo Ke et al. [24] used co-integration analysis and state space model to empirically analyze the long-term equilibrium relationship between energy consumption and economic growth in the Beijing-Tianjin-Hebei region from 1980 to 2012 and their reciprocal causation. The high energy input has an obvious role in promoting economic growth. At the same time, changes in energy elasticity are greatly affected by economic development policies. Chen Huan et al. [25][26] discussed the weak decoupling between energy carbon emission and economic growth in the Beijing-Tianjin-Hebei region from 1998 to 2015, and it fell short of achieving strong decoupling. He Yin et al. [27] quantitatively and comprehensively analyzed the spatial-temporal evolution and decoupling degree of environmental resources and economic growth in the BeijingTianjin-Hebei region from 2000 to 2013, and made it clear that the decoupling index weakened after 2009, but the pressure on environmental resources still existed. Wang Zebo [28] used structural vector autoregression model to empirically analyze the response characteristics of energy consumption in Beijing, Tianjin and Hebei to the impact of urbanization rate: Beijing has a positive response, Tianjin has a negative response and tends to be stable in the medium and long term, and Hebei has a cyclical effect of "being first negative and then positive" after a lag of 3 periods. Wang Zhongyu [29] used the LYQ decoupling model and the Granger causality test model to empirically analyze the weak decoupling between carbon emission and economic growth in the Beijing-Tianjin-Hebei region from 1995 to 2014, and there was a two-way causal relationship between energy consumption and carbon emission. However, there was a oneway causal relationship between economic growth, energy consumption, and carbon emission. Wang Fengting et al. [30] used the decoupling model and the LMDI model to evaluate and analyze the relationship between industrial energy carbon emission and economic growth in the BeijingTianjin-Hebei region from 1996 to 2017 from weak decoupling to strong decoupling. The intensity of carbon emission and the intensity of energy consumption became the main factors for effectively suppressing the carbon emission. Wang Fengyun et al. [31][32] used exploratory spatial data analysis and fixed effect regression model to reach the research conclusions that the energy intensity of Beijing-Tianjin-Hebei region fails to reflect significant spatial correlation as a whole, and energy intensity has a significant positive correlation with industrial structure, technological progress, and property rights arrangements, and has a significant negative correlation with investment and government regulation. The development of the tertiary industry plays a significant role in optimizing the energy consumption structure of the Beijing-Tianjin-Hebei region, and energy prices are not significant in guiding the marketization of the optimization of energy consumption structure in Beijing-Tianjin-Hebei region.

A review of the literature shows that there are some shortcomings in the decoupling evaluation of economic development and energy consumption in the Beijing-Tianjin-Hebei region. The existing results mainly focus on the decoupling of the total energy consumption in the Beijing-Tianjin-Hebei 
region from 1998 to 2015 and the decoupling of industrial energy consumption in the three regions of Beijing, Tianjin and Hebei from 1996 to 2017, laying particular emphasis on introducing energy consumption as an intermediate variable that affects carbon emission indirectly into the decomposition model, and analyzing the driving factors for the decoupling of economic development and energy carbon emission. However, the decoupling mechanism of energy consumption in different industries is not all the same. In practice, the total energy consumption and energy consumption of different industries should be considered as a whole, the decoupling situation of economic development and energy consumption in the Beijing-TianjinHebei region should be evaluated, and the decoupling of economic development and energy consumption in the Beijing-Tianjin-Hebei region should also be evaluated through the decomposition of the driving effect of changes in energy consumption in different industries. In view of this, centering on the economic development and changes in energy consumption in the BeijingTianjin-Hebei region and its industries, this article adopts a Complete Decomposition Model to conduct the decomposition of the driving effect of the decoupling of energy consumption in the three industries in the Beijing-Tianjin-Hebei region, construct an evaluation model for the decoupling of economic development and energy consumption under dual control action, determine the elastic coefficient of decoupling between economic development and energy consumption in the Beijing-Tianjin-Hebei region, evaluate the decoupling situation of economic development and energy consumption in the Beijing-Tianjin-Hebei region, and deeply analyze and demonstrate the driving mechanism of decoupling energy consumption in the Beijing-Tianjin-Hebei region. Finally, corresponding countermeasures and suggestions are put forward to provide decision support for the government administrative department of Beijing, Tianjin and Hebei to accelerate the decoupling of energy consumption for economic development in the Beijing-TianjinHebei region.

\section{RESEARCH METHOD DESIGN}

\subsection{Decomposition Model of Driving Effect of Economic Development and Energy Consumption Changes}

The industry decomposition of the total energy consumption growth changes in the $i$ region of Beijing-Tianjin-Hebei region during the $t_{1}$ period can be expressed as follows:

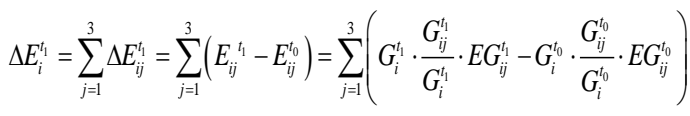

In formula (1), $\Delta E_{i}^{t_{1}}$ represents the changes of increase in total energy consumption in the $i$ region of Beijing-Tianjin-Hebei region in the period ${ }^{t_{1}}$ compared to the period $t_{0} \quad(i=1,2,3$ represents Beijing, Tianjin, and Hebei respectively); $\Delta E_{i j}^{t_{i}}$ growth of the ${ }^{j}$ industry in the $i$ region of the Beijing-Tianjin-Hebei region in the period $t_{1}$ compared to the period $t_{0}(j=1,2,3$ represents the primary, secondary and tertiary industries respectively); $E_{i j}^{t_{1}}$ and $E_{i j}^{t_{0}}$ respectively represent the energy consumption of the ${ }^{j}$ industry in the ${ }^{i}$ region of Beijing-Tianjin-Hebei region in the $t_{1}$ period and the ${ }^{t_{0}}$ period; $G_{i}^{t_{1}}$ and $G_{i}^{t_{0}}$ respectively represent the total economic output value of the $i$ region of Beijing-Tianjin-Hebei region during the $t_{1}$ period and the $t_{0}$ period; $G_{i j}^{t_{i}}$ and $G_{i j}^{t_{0}}$ respectively represent the economic added value of the ${ }^{j}$ industry in the ${ }^{i}$ region of Beijing-TianjinHebei region in the ${ }^{t_{1}}$ period and the ${ }^{t_{0}}$ period; $\frac{G_{i j}^{t}}{G_{i}^{t}}$ and $\frac{G_{i}^{t 0}}{G_{i}^{t i}}$ respectively represent the proportion of the economic added value of the $j$ industry in the $i$ region of the Beijing-Tianjin-Hebei region in the total economic output value in the ${ }^{t_{1}}$ period and the $t_{0}$ period (namely, the proportion of the industrial structure); $E G_{i j}^{t_{1}}$ and $E G_{i j}^{t_{0}}$ respectively represent the 10,000-yuan value-added energy consumption (namely, the energy consumption intensity) of the $j$ industry in the $i$ region of Beijing-TianjinHebei region in the ${ }^{t_{1}}$ period and the ${ }^{t_{0}}$ period. 
According to formula (1), the energy consumption changes of different industries in the Beijing-Tianjin-Hebei region are mainly affected by changes in industrial economic added value, industrial structure and energy consumption intensity. That is, the driving effect of the decoupling of energy consumption in different industries in the Beijing-Tianjin-Hebei region can be decomposed into structural adjustment effect and technological progress effect. For this reason, the structural adjustment effect and technological progress effect of the decoupling of energy consumption of the $j$ industry in the $i$ region of the Beijing-Tianjin-Hebei region have been determined, which can be expressed as:

$$
\begin{aligned}
& \Delta E_{i j}^{t_{1}}=\Delta E_{i j s}^{t_{i}}+\Delta E_{i j e}^{t_{i}} \\
& \left\{\begin{array}{l}
\Delta E_{i j s}^{t_{1}}=E G_{i j}^{t_{0}}\left(G_{i}^{t_{1}} \cdot \frac{G_{i j}^{t_{1}}}{G_{i}^{t_{1}}}-G_{i}^{t_{0}} \cdot \frac{G_{i j}^{t_{0}}}{G_{i}^{t_{0}}}\right)+\frac{1}{2}\left(E G_{i j}^{t_{1}}-E G_{i j}^{t_{0}}\right)\left(G_{i}^{t_{1}} \cdot \frac{G_{i j}^{t_{1}}}{G_{i}^{t_{1}}}-G_{i}^{t_{0}} \cdot \frac{G_{i j}^{t_{0}}}{G_{i}^{t_{0}}}\right) \\
\Delta E_{i j e}^{t_{1}}=G_{i}^{t_{0}} \cdot \frac{G_{i j}^{t_{0}}}{G_{i}^{t_{0}}}\left(E G_{i j}^{t_{1}}-E G_{i j}^{t_{0}}\right)+\frac{1}{2}\left(E G_{i j}^{t_{1}}-E G_{i j}^{t_{0}}\right)\left(G_{i}^{t_{1}} \cdot \frac{G_{i j}^{t_{1}}}{G_{i}^{t_{1}}}-G_{i}^{t_{0}} \cdot \frac{G_{i j}^{t_{0}}}{G_{i}^{t_{0}}}\right)
\end{array}\right.
\end{aligned}
$$

In formula (2), $\Delta E_{i j s}^{t_{1}}$ represents the structural adjustment effect of the changes in energy consumption of the ${ }^{j}$ industry in the ${ }^{i}$ region of Beijing-Tianjin-Hebei region in the period $t_{1}$ compared to the period ${ }^{t_{0}}$, that is, the change in energy consumption caused by the adjustment of industrial structure; $\Delta E_{i j e}^{t_{0}}$ represents the technological progress effect of the changes in energy consumption of the $j$ industry in the $i$ region of the Beijing-Tianjin-Hebei region in the period ${ }^{t_{1}}$ compared to the period ${ }^{t_{0}}$, that is, the change in energy consumption caused by changes in energy consumption intensity caused by industrial technological progress.

\subsection{Evaluation Model of Decoupling Economic Development and Energy Consumption}

According to formulas (1) and (2), this article draws on the decoupling discrimination framework constructed by the OECD [4] to construct a decoupling evaluation model for economic development and energy consumption under dual control action, determine the elastic coefficient of decoupling between economic development and energy consumption in the Beijing-Tianjin-Hebei region, and determine the decoupling situation of economic development and energy consumption in the Beijing-Tianjin-Hebei region (see "Table 1").

Table 1. Evaluation model of decoupling economic development and energy consumption under dual control

\begin{tabular}{|c|c|c|c|c|}
\hline \multirow[b]{2}{*}{ Changes in output value } & \multicolumn{2}{|c|}{ Changes in dual control action indicators } & \multirow[b]{2}{*}{$\begin{array}{l}\text { Decoupling elastid } \\
\text { coefficient }\end{array}$} & \multirow[b]{2}{*}{ Decoupling situation } \\
\hline & $\begin{array}{l}\text { Total energy } \\
\text { control changes }\end{array}$ & \begin{tabular}{l|lr} 
consumption & $\begin{array}{lr}\text { Energy } & \text { consumption } \\
\text { intensity control changes }\end{array}$
\end{tabular} & & \\
\hline Increase & Decrease & Improve & $<0$ & Strong decoupling \\
\hline Increase & Increase & Improve & $(0,0.8)$ & Weak decoupling \\
\hline Decrease & Decrease & Improve & $>1.2$ & Declining decoupling \\
\hline Decrease & Increase & Reduce & $<0$ & Strong negative decoupling \\
\hline Decrease & Decrease & Reduce & $(0,0.8)$ & Weak negative decoupling \\
\hline Increase & Increase & Reduce & $>1.2$ & $\begin{array}{l}\text { Expansionary negative } \\
\text { decoupling }\end{array}$ \\
\hline Increase & Increase & - & $(0.8,1.2)$ & Growth connection \\
\hline Decrease & Decrease & - & $(0.8,1.2)$ & Declining connection \\
\hline
\end{tabular}
action

In "Table 1", the Tapio elastic coefficient method is used to determine the decoupling elastic coefficient between the economic industrial development of the Beijing-Tianjin-Hebei region and energy consumption, which can be expressed as: 
$T_{i j}^{t_{i}}=\frac{\Delta E_{i j}^{t_{i}} / E_{i j}^{t_{0}}}{\Delta G_{i j}^{t_{j}} / G_{i j}^{t_{0}}}$

In formula (3), ${ }^{T_{i j}}$ represents the decoupling elastic coefficient of the economic development and energy consumption of the ${ }^{j}$ industry in the $i$ region of Beijing-Tianjin-Hebei region in the $t_{1}$ period.

Summing up the above, through the decomposition of the driving effect of energy consumption changes in different industries in the Beijing-Tianjin-Hebei region in different periods, the decoupling situation of economic industrial development and energy consumption in the Beijing-Tianjin-Hebei region is determined, and the driving mechanism of the decoupling of economic development and energy consumption in the Beijing-Tianjin-Hebei region is comprehensively analyzed.

\section{EMPIRICAL RESEARCH}

This article uses literature retrieval and research methods to collect policies and related data on the economic development and energy consumption of the Beijing-Tianjin-Hebei region and its different industries. The research data in this article mainly comes from the "China Energy Statistical Yearbook", "Beijing Statistical Yearbook", "Tianjin Statistical Yearbook" and "Hebei Statistical Yearbook". During the period from the "8th FiveYear Plan" to the "13th Five-Year Plan", with the acceleration of China's urbanization and industrialization, the Beijing-Tianjin-Hebei region has accelerated economic structural adjustment and transformation and upgrading. The proportion of the primary and secondary industry structure continues to decline rapidly, and the proportion of the tertiary industry structure continues to rise rapidly. Beijing's economic development has entered a post-industrial period, with the tertiary industry dominating. Among them, the average proportions of the primary industry and the secondary industry structure decreased from 6.3\% and $46.6 \%$ to $0.4 \%$ and $19.0 \%$ respectively. The average proportion of the tertiary industry structure rose from $47.2 \%$ to $80.6 \%$. Tianjin's economic development has entered the late stage of industrialization, and the tertiary industry has gradually become the leading industry, but the secondary industry structure still accounts for a relatively high proportion. Among them, the average proportions of the primary and secondary industrial structure dropped from $7.1 \%$ and $56.7 \%$ to $1.0 \%$ and $41.2 \%$ respectively, and the average proportion of the tertiary industry structure rose from $36.2 \%$ to $57.7 \%$. Hebei's economic development is still in the middle of industrialization, dominated by the secondary industry, and the secondary and tertiary industries are developing simultaneously. Among them, the average proportion of the primary industry structure dropped from $20.6 \%$ to $9.8 \%$. The average proportion of the secondary industry structure rose from 46.5\% in the "8th Five-Year Plan" period to $53.0 \%$ in the "11th Five-Year Plan" period, and then fell to $46.2 \%$ in the "13th Five-Year Plan" period. The average proportion of the tertiary industry structure increased from $32.9 \%$ to $44.0 \%$. By the "13th Five-Year Plan" period, the average proportion of the tertiary industry structure has not exceeded that of the secondary industry.

\subsection{Decomposition of the Driving Effect of Decoupling Industrial Energy Consumption in Beijing-Tianjin-Hebei Region and Its Decoupling Situation}

From the "8th Five-Year Plan" to the "13th Five-Year Plan" period, the decomposition of the driving effect of the decoupling of industrial energy consumption in the Beijing-Tianjin-Hebei region and its decoupling situation are shown in "Table 2", "Table 3" and "Table 4." 
Table 2. Decomposition of the driving effect of Beijing's industrial energy consumption changes in different planning periods and its decoupling situation

\begin{tabular}{|c|c|c|c|c|c|}
\hline Industry & Planning period & $\begin{array}{l}\text { Structural } \\
\text { adjustment effect }\end{array}$ & $\begin{array}{l}\text { Technological } \\
\text { progress effect }\end{array}$ & $\begin{array}{l}\text { Decoupling } \\
\text { elastic coefficient }\end{array}$ & Decoupling situation \\
\hline \multirow{6}{*}{$\begin{array}{l}\text { The } \\
\text { primary } \\
\text { industry }\end{array}$} & The 8th Five-Year Plan & 59.94 & -45.24 & 0.21 & Weak decoupling \\
\hline & The 9th Five-Year Plan & 8.51 & -24.11 & -1.66 & \multirow{2}{*}{ Strong decoupling } \\
\hline & The 10th Five-Year Plan & 10.78 & -30.18 & -1.56 & \\
\hline & The 11th Five-Year Plan & 31.31 & -18.21 & 0.38 & Weak decoupling \\
\hline & The 12th Five-Year Plan & 11.06 & -24.96 & -1.11 & Strong decoupling \\
\hline & The 13th Five-Year Plan & -10.87 & -13.03 & 2.02 & Declining decoupling \\
\hline \multirow{6}{*}{$\begin{array}{l}\text { The } \\
\text { secondary } \\
\text { industry }\end{array}$} & The 8th Five-Year Plan & 1947.95 & -1339.65 & 0.24 & \multirow{2}{*}{ Weak decoupling } \\
\hline & The 9th Five-Year Plan & 1153.15 & -1056.75 & 0.07 & \\
\hline & The 10th Five-Year Plan & 1744.62 & -1805.72 & -0.03 & Strong decoupling \\
\hline & The 11th Five-Year Plan & 1269.33 & -1268.93 & 0.0003 & Weak decoupling \\
\hline & The 12th Five-Year Plan & 644.40 & -1105.80 & -0.57 & Strong decounling \\
\hline & The 13th Five-Year Plan & 352.34 & -419.84 & -0.17 & sionig necoupinit \\
\hline \multirow{6}{*}{$\begin{array}{l}\text { The } \\
\text { tertiary } \\
\text { industry }\end{array}$} & The 8th Five-Year Plan & 1024.72 & -907.32 & 0.07 & \multirow{6}{*}{ Weak decoupling } \\
\hline & The 9th Five-Year Plan & 838.41 & -390.21 & 0.44 & \\
\hline & The 10th Five-Year Plan & 1251.78 & -560.98 & 0.47 & \\
\hline & The 11th Five-Year Plan & 1768.11 & -885.41 & 0.42 & \\
\hline & The 12th Five-Year Plan & 1666.39 & -1008.19 & 0.34 & \\
\hline & The 13th Five-Year Plan & 1443.13 & -1074.33 & 0.22 & \\
\hline
\end{tabular}

a Note: According to the data of Beijing Energy Statistical Yearbook, the data of the "13th Five-Year Plan" period is only the data of 2016-2018.

According to "Table 2", the structural adjustment effect of energy consumption in Beijing's primary and secondary industries has generally declined. During the period from the "9th Five-Year Plan" to the "12th Five-Year Plan", the absolute value of the technological progress effect of the energy consumption of the primary and secondary industries generally exceeded the structural adjustment effect, the decoupling elastic coefficient was negative (the decoupling elastic coefficient of energy consumption in the secondary industry during the "11th Five-Year Plan" period tended to 0), and the development and energy consumption of the primary and secondary industries showed a relatively stable "strong decoupling" situation. By the "13th Five-Year Plan" period, the development of the secondary industry and energy consumption have maintained a "strong decoupling" situation. And the structural adjustment effect of the energy consumption of the primary industry was significant, with negative growth in both its structural adjustment effect and technological progress effect. However, due to the decline in the added value of the primary industry, the development of the primary industry and energy consumption showed a situation of "declining decoupling". At the same time, the gap between the absolute value of the technological progress effect of the energy consumption of the tertiary industry and the structural adjustment effect has shown a trend of "quickly expanding first and then slowly shrinking", and the decoupling elastic coefficient rose overall. The absolute value of the technological progress effect of energy consumption in the tertiary industry was still lower than the structural adjustment effect, and the development of the tertiary industry and energy consumption still showed a "weak decoupling" situation. 
Table 3. Decomposition of the driving effect of Beijing-Tianjin-Hebei region's industrial energy consumption changes in different planning periods and its decoupling situation

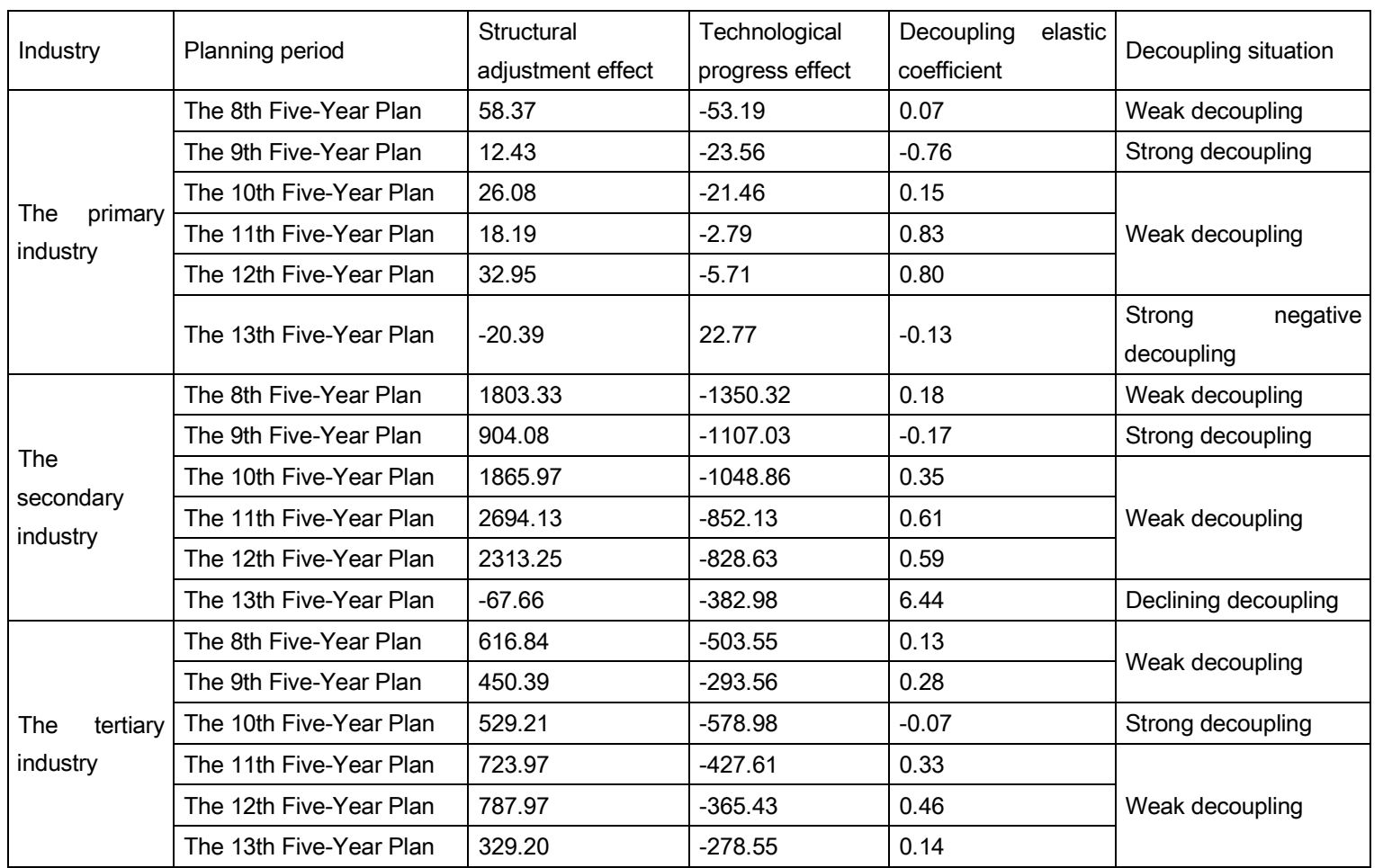

a Note: According to the data of Tianjin Energy Statistical Yearbook, the data of the "13th Five-Year Plan" period is only the data of 2016-2018.

According to "Table 3", the structural adjustment effect of energy consumption in Tianjin's primary and secondary industries from the "8th Five-Year Plan" to the "12th Five-Year Plan" period has fluctuated downward. However, the structural adjustment effect of energy consumption in the primary and secondary industries was generally greater than the absolute value of the technological progress effect. Except for the "9th Five-Year Plan" period, the decoupling elastic coefficients were all positive, and the development and energy consumption of the primary and secondary industries all showed a "weak decoupling" situation. During the "13th Five-Year Plan" period, due to the decline in the added value of the secondary industry, the development of the secondary industry and energy consumption showed a "declining decoupling" situation. While the added value of the primary industry declined, the energy consumption increased, and the energy consumption efficiency fell, the development of the primary industry and energy consumption showed a "strong negative decoupling" situation. At the same time, the gap between the structural adjustment effect of the tertiary industry's energy consumption and the absolute value of the technological progress effect was manifested in an alternating changing situation of "expanding-shrinking". However, except for the "10th Five-Year Plan" period, the absolute value of the technical progress effect of the tertiary industry's energy consumption was still lower than the structural adjustment effect, and the development of the tertiary industry and energy consumption presented a stable "weak decoupling" situation. 
Table 4. Decomposition of the driving effect of Hebei's industrial energy consumption changes in different planning periods and its decoupling situation

\begin{tabular}{|c|c|c|c|c|c|}
\hline Industry & Planning period & $\begin{array}{l}\text { Structural } \\
\text { adjustment effect }\end{array}$ & $\begin{array}{l}\text { Technological } \\
\text { progress effect }\end{array}$ & $\begin{array}{l}\text { Decoupling elastic } \\
\text { coefficient }\end{array}$ & Decoupling situation \\
\hline \multirow{6}{*}{$\begin{array}{l}\text { The } \\
\text { primary } \\
\text { industry }\end{array}$} & The 8th Five-Year Plan & 370.43 & -415.72 & -0.08 & Strong decoupling \\
\hline & The 9th Five-Year Plan & 82.43 & -11.25 & 0.85 & \multirow{3}{*}{ Weak decoupling } \\
\hline & The 10th Five-Year Plan & 232.33 & -33.73 & 0.82 & \\
\hline & The 11th Five-Year Plan & 381.73 & -238.91 & 0.32 & \\
\hline & The 12th Five-Year Plan & 199.28 & -244.10 & -0.19 & Strong decoupling \\
\hline & The 13th Five-Year Plan & -19.64 & 54.80 & -1.87 & $\begin{array}{ll}\text { Strong negative } \\
\text { decoupling }\end{array}$ \\
\hline \multirow{6}{*}{$\begin{array}{l}\text { The } \\
\text { secondary } \\
\text { industry }\end{array}$} & The 8th Five-Year Plan & 7055.21 & -4593.19 & 0.26 & \multirow{2}{*}{ Weak decoupling } \\
\hline & The 9th Five-Year Plan & 4503.02 & -4148.36 & 0.06 & \\
\hline & The 10th Five-Year Plan & 7891.90 & 1298.37 & 1.24 & $\begin{array}{l}\text { Expansionary } \\
\text { negative decoupling }\end{array}$ \\
\hline & The 11th Five-Year Plan & 13400.47 & -9021.30 & 0.27 & \multirow{2}{*}{ Weak decoupling } \\
\hline & The 12th Five-Year Plan & 6370.75 & -4239.92 & 0.30 & \\
\hline & The 13th Five-Year Plan & -2473.96 & 2887.99 & -0.18 & $\begin{array}{|ll|}\begin{array}{l}\text { Strong negative } \\
\text { decoupling }\end{array} & \\
\end{array}$ \\
\hline \multirow{6}{*}{$\begin{array}{l}\text { The tertiary } \\
\text { industry }\end{array}$} & The 8th Five-Year Plan & 284.07 & -61.65 & 0.70 & Weak decoupling \\
\hline & The 9th Five-Year Plan & 351.78 & 64.81 & 1.26 & \begin{tabular}{|l|} 
Expansionary \\
negative decoupling
\end{tabular} \\
\hline & \begin{tabular}{|l|} 
The 10th Five-Year Plan \\
\end{tabular} & 709.62 & -131.22 & 0.77 & \multirow{4}{*}{ Weak decoupling } \\
\hline & The 11th Five-Year Plan & 1313.42 & -633.61 & 0.44 & \\
\hline & The 12th Five-Year Plan & 1279.82 & -440.63 & 0.60 & \\
\hline & The 13th Five-Year Plan & 920.35 & -707.48 & 0.21 & \\
\hline
\end{tabular}

According to "Table 4", from the "9th FiveYear Plan" to the "11th Five-Year Plan" period, the structural adjustment effect of Hebei's primary and secondary industries' energy consumption fluctuated downward, the absolute value of the technical progress effect of energy consumption in the primary and secondary industries was significantly lower than the structural adjustment effect, the decoupling elastic coefficient was generally positive, and the development of the primary and secondary industries and energy consumption generally showed a relatively stable "weak decoupling" situation. By the "12th FiveYear Plan" period, the development of the secondary industry and energy consumption still showed a "weak decoupling" situation, the absolute value of the technological progress effect of the energy consumption of the primary industry exceeded the structural adjustment effect, and the development of the primary industry and energy consumption showed a "strong decoupling" situation. By the "13th Five-Year Plan" period, the structural adjustment effect of energy consumption in the primary and secondary industries was significant, and both achieved negative growth. However, the added value of the primary and secondary industries declined, the energy consumption increased, the energy consumption efficiency fell, and the development of the primary and secondary industries and energy consumption showed a "strong negative decoupling" situation. Meanwhile, the absolute value of the technological progress effect of energy consumption in the tertiary industry was lower than the structural adjustment effect from beginning to end, and the development of the tertiary industry and energy consumption generally showed a "weak decoupling" situation.

\subsection{Analysis of the Driving Mechanism of Decoupling Economic Development and Energy Consumption in Beijing- Tianjin-Hebei Region}

According to "Table 2" to "Table 4", firstly, the transformation and upgrading of Beijing's industrial 
structure and the strengthening of dual control action have achieved remarkable results. By the middle of the "13th Five-Year Plan", the structural adjustment effect of the primary industry's energy consumption has gradually achieved negative growth, and it plays a significant role together with the technological progress effect to accelerate the decoupling of the development of the primary industry from energy consumption. The technological progress effect on energy consumption in the secondary industry plays a significant role. At the same time, because the structural adjustment effect of energy consumption in the tertiary industry still plays a leading role, the technological progress effect has not played a significant role, and the energy consumption of the tertiary industry has not achieved negative growth. On the whole, Beijing has not yet fully reached the peak of energy consumption and the "inflection point" of energy consumption increase. Beijing's economic development and energy consumption are generally "weakly decoupled". The technological progress effect in the primary and secondary industries has become the main driving force for accelerating the decoupling of the development of the primary and secondary industries from energy consumption.

Secondly, the transformation and upgrading of Tianjin's industrial structure and the strengthening of dual control action have not achieved significant results. By the "13th Five-Year Plan" period, the structural adjustment effects of energy consumption in the primary and secondary industries have gradually achieved negative growth. The structural adjustment effect and the technological progress effect of the energy consumption of the secondary industry play a significant role together to accelerate the decoupling of the development of the secondary industry from energy consumption. And the technological progress effect on energy consumption in the primary industry has not played a significant role. At the same time, the structural adjustment effect of the energy consumption of the tertiary industry still plays a leading role, and the energy consumption of the tertiary industry has not achieved negative growth. In general, Tianjin has not yet reached the peak of energy consumption and the "inflection point" of energy consumption increase. Tianjin's economic development and energy consumption present a relatively stable "weak decoupling" situation. It only achieves a "strong decoupling" situation during the "13th FiveYear Plan" period, which mainly depends on the decline in life energy consumption. The technological progress effect is still the main driving force for accelerating the decoupling of Tianjin's economic development and energy consumption, but it has not played a significant role.

Thirdly, the result of the transformation and upgrading of Hebei's industrial structure and strengthening of dual control action is not obvious. By the "13th Five-Year Plan" period, the structural adjustment effect of energy consumption in the primary and secondary industries has gradually achieved negative growth, while the technological progress effect of energy consumption in the primary and secondary industries has not played a significant role. At the same time, although the technological progress effect of energy consumption in the tertiary industry has increased, the structural adjustment effect of energy consumption in the tertiary industry still plays a leading role. On the whole, Hebei has not yet reached the peak of energy consumption and the "inflection point" of energy consumption increase. Hebei's economic development and energy consumption show a relatively stable "weak decoupling" situation. The technological progress effect is still the main driving force for accelerating the decoupling of Hebei's economic development and energy consumption, but it has not played a significant role.

In summary, the technological progress effect is the main driving force for accelerating the decoupling of economic development and energy consumption in the Beijing-Tianjin-Hebei region. Since the "9th Five-Year Plan" period, as local governments in the Beijing-Tianjin-Hebei region have increased their energy conservation and emission reduction policies, industrial enterprises have been urged to speed up the improvement of production technology and increase energy consumption efficiency. The energy consumption of the secondary industry in the Beijing-Tianjin region has been controlled. Among them, Beijing has the best industrial structure, with low-energy consumption, low-pollution, and high value-added industries occupying the dominant position. Compared with Tianjin and Hebei, Beijing's energy conservation and emission reduction policies have high standards, strict regulatory measures, and strong implementation intensities, effectively encouraging Beijing's industrial enterprises to accelerate energy-saving technological progress and increase the intensity of energy consumption in Beijing's industries. Tianjin actively promotes various energy-saving technologies to increase the intensity of industrial energy saving. Hebei's 
industrial structure is relatively backward. Industries with high energy consumption, high pollution and low added value account for a relatively large proportion, and industrial energy consumption still maintains a low growth rate, showing that Hebei's industrial energy conservation concept has not been strictly implemented, and its focus on short-term goals in the formulation and implementation of energy conservation and emission reduction policies is not conducive to enhancing the long-term effectiveness of the implementation of energy conservation and emission reduction goals. Facing the downward pressure on the economy, Hebei still has the phenomenon of stabilizing economic growth at the expense of increasing energy consumption. Therefore, Hebei urgently needs to increase the intensity of industrial energy consumption, enhance the technological progress effect of industrial energy consumption, and accelerate the decoupling of industrial economic development and energy consumption in Hebei. In addition, the BeijingTianjin-Hebei region urgently needs to improve the energy consumption intensity of the tertiary industry by improving energy science and technology innovation capabilities. Moreover, it needs to accelerate the transformation and upgrading of the tertiary industrial structure, and quickly reduce the structural adjustment effect of the tertiary industry's energy consumption. In this way, the gap between the absolute value of the technological progress effect and the structural adjustment effect can be narrowed, and the decoupling of the development of the tertiary industry and energy consumption in the BeijingTianjin-Hebei region can be ensured.

\section{CONCLUSION}

Combining the structural adjustment and technological progress of different industries in the Beijing-Tianjin-Hebei region, this article decomposes the driving effect of the increase in industrial energy consumption, constructs an evaluation model for the decoupling of the economic development and energy consumption of the Beijing-Tianjin-Hebei region under the dual control action, dynamically evaluates the decoupling situation of economic development and energy consumption in the Beijing-Tianjin-Hebei region in different planning periods, and deeply analyzes and demonstrates the driving mechanism of energy consumption decoupling in the BeijingTianjin-Hebei region. Researches show that, compared with major urban agglomerations in
China, the economic development and industrial energy consumption in the Beijing-Tianjin-Hebei region are more affected by location factors, energy resources endowments and constraints, and related government policies. The energy resources endowments and the industrial energy consumption structure in the Beijing-Tianjin-Hebei region have significant spatial heterogeneity. The service industry has become the main driving force of Beijing's economic and social development, while industry remains the main driving force for the economic and social development of Tianjin and Hebei. It can be seen from the research results that, firstly, the economic development and energy consumption in the Beijing-Tianjin-Hebei region have shown a relatively stable "weak decoupling" situation for a long time. Beijing's dual control action has achieved remarkable results, while the effect of dual control action in the Tianjin-Hebei region is not obvious. The energy consumption efficiency of the tertiary industry in Beijing has improved faster than that in the Tianjin-Hebei region, and the energy consumption efficiency of the primary and second industries in Hebei has improved faster than that in the Beijing-Tianjin region. Secondly, by the "13th Five-Year Plan" period, the Beijing-Tianjin-Hebei region has not yet reached the peak of energy consumption and the "inflection point" of energy consumption increase. The effect of technological progress is the main driving force for accelerating the decoupling of economic development and energy consumption in the Beijing-Tianjin-Hebei region. Thirdly, by the "13th Five-Year Plan" period, the structural adjustment effect of the energy consumption of the primary industry in the Beijing-Tianjin-Hebei region has played a significant role, and the structural adjustment effect of the energy consumption of the secondary industry in the Tianjin-Hebei region has also played a significant role. In the future, the structural adjustment effect will become an important driving force for the decoupling of energy consumption and economic development in the Beijing-Tianjin-Hebei region together with the effect of technological progress. Fourthly, the structural adjustment effect of the tertiary industry energy consumption in the BeijingTianjin-Hebei region has not yet played a significant role. It is urgent to accelerate the structural transformation and upgrading of the tertiary industry, strengthen the structural adjustment effect of the tertiary industry energy consumption, and improve the energy consumption efficiency of the tertiary industry by improving the ability of energy technology innovation. 
In order to realize the decoupling of economic development and energy consumption in the Beijing-Tianjin-Hebei region, it is necessary to implement the concept of green development, accelerate the formulation of green energy development planning, and intensify the implementation of energy resources or carbon emission control assessment, or energy conservation and emission reduction and environmental protection policies by government administrative departments. Moreover, it is needed to break down administrative barriers, accelerate the flow of energy-saving technologies in different administrative regions, and strengthen the guiding role of technological progress effect. On the premise of strictly controlling the zero increase in energy consumption of the primary industry in the Beijing-Tianjin-Hebei region, it is necessary to intensify the adjustment intensity of the industrial structure in the Beijing-Tianjin-Hebei region, increase the intensity of industrial energy consumption in the Tianjin-Hebei region, and improve the technological progress effect in energy consumption in Tianjin and Hebei. At the same time, efforts should be made to strengthen the guiding role of the tertiary industry transformation and upgrading and dual control action policies in the Beijing-Tianjin-Hebei region in accordance with local conditions, improve the energy consumption intensity of the tertiary industry, and rapidly increase the technological progress effect of the tertiary industry's energy consumption by improving energy science and technology innovation capabilities. Moreover, it is necessary to speed up the transformation and upgrading of the tertiary industry, optimize the structure of the tertiary industry, and accelerate the role of the structural adjustment effect of the tertiary industry's energy consumption.

\section{AUTHORS' CONTRIBUTIONS}

Dan $\mathrm{Wu}$ is responsible for experimental design and writing the manuscript, Chenhui $\mathrm{Ji}$ is responsible for analyzing data and writing the manuscript.

\section{REFERENCES}

[1] Carter A.P. The economics of technological change [J]. 1966,214:25-31.

[2] FRIEDRICH S B, RAINER K. Wieviel umwelt raucht der mensch? mips-das mass fuer oekologisches wirtschaften [M]. Basel, Boston: Berlin, 1993.

[3] WEIZSÄCKER E U V, LOVINS A B, LOVINS L H, et al. Factor four: doubling wealth, halving resource use $[\mathrm{M}]$. London: Earthscan, 1997.

[4] OECD. Indicators to measure decoupling of environmental pressure from economic growth [R]. Paris: OECD, 2002.

[5] DE BRUYN S M, OPSCHOOR J B. Developments in the throughput-in-come relationship: theoretical and empirical observations $[\mathrm{J}]$. Ecological economics, 1997,20(3):255-268.

[6] TAPIO P. Towards a theory of decoupling: Degrees of decoupling in the EU and the case of road traffic in Finland between 1970 and 2001 [J]. Journal of Transport Policy, 2005(12):137-151.

[7] VEHMAS J, KAIVO-OJA J, LUUKKANEN $\mathrm{J}$, et al. Global trends of linking environmental stress and economic growth [M]. Turku: Finland Futures Research Centre, 2003, 6-9.

[8] AYRES R U, AYRES L W, WARR B, et al. Energy, power and work in the US economy,1900-1998 [J]. Energy, 2003,28(3):219-273.

[9] Kraft J, Kraft A. On the relationship between energy and GNP. The Journal of Energy and Development, 1978, 3(2): 401-403. Paul S, Bhattacharya R N. Causality between energy consumption and economic growth in India: A note on conflicting results $[\mathrm{J}]$. Energy Economics, 2004, 26(6): 977-983.

[10] CLIMENT F, PARDO A. Decoupling factors on the energy-output linkage: The Spanish case [J]. Energy Policy, 2007, 35 (1):522-528.

[11] VAN DER VOET E, VAN OERS L, MOLL S, et al. Development of indicators to assess decoupling of economic development and environmental pressure in the EU-25 and AC3 countries [J]. Policy Review on Decoupling. RA Leiden, the Netherlends, 2005.

[12] Pirlogea C, Cicea C. Econometric perspective of the energy consumption and economic growth relation in European Union [J]. Renewable and Sustainable Energy Reviews, 2012, 16(8): 5718-5726. 
[13] Liu Yijun, Wang Li, Niu Wenyuan. Decoupling Research Between Economic Development and Energy Consumpution of China's Cities [J]. China Population, Resources and Environment, 2011, 21(01): 70-77. (in Chinese)

[14] Wang Lei, Wei Houkai. The Impacts of Chinese Urbanization on Energy Consumption [J]. Resources Science, 2014, 36(6): 12351243. (in Chinese)

[15] Ye Cuihong, Zhao Yulin. Empirical Analysis on Energy Intensity Difference of Chinese Provincial Regions Based on Cusp Catastrophe Model [J]. Forum on Science and Technology in China, 2014(10): 132-137. (in Chinese)

[16] Yang J, Zhang W, Zhang Z. Impacts of urbanization on renewable energy consumption in China [J]. Journal of Cleaner Production, 2016, 114: 443-451.

[17] Zhang Kuanqi, Yan Bin, Shen Qianling. The Relationship between Energy Consumption and Economic Growthin Beijing Based on the Extended Production Function - Analysis from the perspective of Toda-Yamomoto causality test and decoupling $[\mathrm{J}]$. Systems Engineering, 2017(9): 79 -86. (in Chinese)

[18] Zhou X, Zhang M, Zhou M, et al. A comparative study on decoupling relationship and influence factors between China's regional economic development and industrial energyrelated carbon emissions [J]. Journal of Cleaner Production, 2017,142: 783 -800.

[19] He Ze, Yang Yu, Song Zhouying, et al. The mutual evolution and driving factors of China's energy consumption and economic growth [J]. Geographical Research, 2018, 37(8): 1528-1540. (in Chinese)

[20] Yue Li, Song Yaqiong, Jiang Lingfeng. National energy efficiency of countries in the "Belt and Road" region and its decoupling from economic growth [J]. Resources Science, 2019,31(5):834-846. (in Chinese)

[21] Li Lianshui, Zhou Yong. Can technological progress improve energy efficiency? - Based on the empirical test of China's industrial sector [J]. Management World, 2006, (10): 8289. (in Chinese)
[22] Wang Huanfang, $\mathrm{Hu}$ Zhenhua. The measurement research on the decoupling relationship between manufacturing sector economic growth and carbon dioxide in China [J]. Studies in Science of Science, 2012, 30(11):1671-1675. (in Chinese)

[23] Yang Liangjie, Wu Wei, Su Qin, Du Zhipeng, Jiang Xiaowei, et al. Carbon Emissions of Transportation Energy Consumption and Its Decoupling Analysis in Jiangsu Province [J]. Resources and Environment in the Yangtze Basin, 2014, 23(10): 1383-1390. (in Chinese)

[24] Guo Ke, Wang Liqun. Summarization on the interaction relation between energy consumption and economic growth in BeijingTianjin-Hebei Area [J]. Urban Problems, 2015(5): 52-59. (in Chinese)

[25] Chen Huan, Zhu Qingyuan, Xin Lu, et al. Research on the Relationship between Economic Growth and Carbon Sources Emissions in the Beijing-Tianjin-Hebei Region - Based on the Application Analysis of Decoupling Theory [J]. Price: Theory \& Practice, 2016(12): 180-183. (in Chinese)

[26] Cheng Haisen, Ma Jing, Fan Xinye, et al. Research on the relationship among energy consumption, economic growth and carbon emission in the Beijing-Tianjin-Hebei Region [J]. Modern Management Science, 2017(11):81-83. (in Chinese)

[27] He Yin, Cai Mantang. Decoupling Relationship between Economic Growth and Resource Environment in Beijing-TianjinHebei Region [J]. Journal of Beijing Institute of Technology (Social Sciences Edition), 2016, 18(05): 33-41. (in Chinese)

[28] Wang Zebo. Dynamic impact of urbanization shocks to the energy consumption in BeijingTianjin-Hebei region [J]. Journal of Arid Land Resources and Environment, 2016, 30(9): 713. (in Chinese)

[29] Wang Zhongyu. The Empirical Study on the Relationship Between Energy Consumption, Carbon Emissions and Economic Growth in Beijing-Tianjin-Hebei $[\mathrm{J}]$. Journal of Industrial Technological \& Economics, 2017, 36(01): 82-92. (in Chinese)

[30] Wang Fengting, Fang Kai, Yu Chang. Decoupling Between Industrial Energy-related 
Carbon Emissions and Economic Growth and Its Driving Factors in Beijing, Tianjin and Hebei Urban Agglomeration - Empirical Study Based on Tapio Decoupling and LMDI Model [J]. Journal of Industrial Technological Economics, (8): 32-40. (in Chinese)

[31] Wang Fengyun, Su Yeqin. Energy consumption structure change and its influencing factors in Beijing-Tianjin-Hebei Region Area [J]. Urban Problems, 2018(8):5967. (in Chinese)

[32] Wang Shaohua, Zhang Wei. Study on Spatial Characteristics of Energy Intensity and Supply-side Path of Consumption Reduction in Beijing-Tianjin-Hebei [J]. Technology Economics, 2019,38(9):113-120. (in Chinese) 